Research Paper

\title{
Mild hypothermia during the reperfusion phase protects mitochondrial bioenergetics against ischemia-reperfusion injury in an animal model of ex-vivo liver transplantation-an experimental study
}

\author{
Rui Miguel Martins ${ }^{1,}{ }^{凶}$, João Soeiro Teodoro ${ }^{2}$, Emanuel Furtado ${ }^{3}$, Rui Caetano Oliveira ${ }^{4}$, José Guilherme \\ Tralhão ${ }^{5}$ Anabela Pinto Rolo², Carlos Marques Palmeira ${ }^{2}$ \\ 1. Department of Surgery, Instituto Português de Oncologia de Coimbra, Coimbra, Portugal \\ 2. Department of Life Sciences, Faculty of Sciences and Technology, University of Coimbra; and Center of Neurosciences and Cell Biology, University of \\ Coimbra, Coimbra, Portugal \\ 3. Unidade de Transplantação Hepática de Crianças e Adultos, Hospitais da Universidade de Coimbra, Centro Hospitalar e Universitário de Coimbra, \\ Coimbra, Portugal \\ 4. Department of Pathology, Centro Hospitalar e Universitário de Coimbra, Coimbra, Portugal \\ 5. Department of Surgery, Hospitais da Universidade de Coimbra, Centro Hospitalar e Universitário de Coimbra, Coimbra, Portugal; Clínica Universitária de \\ Cirurgia III, Faculty of Medicine, University of Coimbra, Coimbra, Portugal; and Center for Investigation on Environment, Genetics and Oncobiology \\ (CIMAGO), Faculty of Medicine, University of Coimbra, Coimbra, Portugal
}

$\triangle$ Corresponding author: Rui Miguel Martins, PhD, MD, Department of Surgery, Instituto Português de Oncologia de Coimbra, Av. Bissaya Barreto 98, 3000-075 Coimbra, Portugal. Email address: r23martins@gmail.com; Telephone number: +351-239400200

(0) The author(s). This is an open access article distributed under the terms of the Creative Commons Attribution License (https://creativecommons.org/licenses/by/4.0/). See http://ivyspring.com/terms for full terms and conditions.

Received: 2019.03.04; Accepted: 2019.08.23; Published: 2019.09.07

\begin{abstract}
The organ preservation paradigm has changed following the development of new ways to preserve organs. The use of machine perfusion to preserve organs appears to have several advantages compared with conventional static cold storage. For liver transplants, the temperature control provided by machine perfusion improves organ preservation. In this experimental study, we measured the effects of different temperatures on mitochondrial bioenergetics during the reperfusion phase. An experimental model of ex-vivo liver transplantation was developed in Wistar rats (Rattus norvegicus). After total hepatectomy, cold static preservation occurred at $4^{\circ} \mathrm{C}$ and reperfusion was performed at $37^{\circ} \mathrm{C}$ and $32^{\circ} \mathrm{C}$ using a Langendorff system. We measured parameters associated with mitochondrial bioenergetics in the livers. Compared with the livers that underwent normothermic reperfusion, mild hypothermia during reperfusion caused significant increases in the mitochondrial membrane potential, the adenosine triphosphate content, and mitochondrial respiration, and a significant reduction in the lag phase (all $P<0.001$ ). Mild hypothermia during reperfusion reduced the effect of ischemia-reperfusion injury on mitochondrial activity in liver tissue and promoted an increase in bioenergetic availability compared with normothermic reperfusion.
\end{abstract}

Key words: hypothermia, mitochondria, bioenergetics, adenosine triphosphate, liver transplantation

\section{Introduction}

The lack of available organs is the principal limitation associated with liver transplantation. To increase the quantity of donor organs, marginal organs have been used, including those from elderly donors and patients with hepatic steatosis, those that have experienced prolonged cold ischemia, and those obtained after cardiac death [1,2]. The use of these poor-quality organs affects the clinical outcomes of liver transplantation, which has led to the development of new ways to preserve organs [3, 4]. Ex-vivo machine perfusion of the liver is an alternative to conventional static cold storage, but 
there is no agreement about the most beneficial temperature $[5,6]$. Another issue that requires resolution is whether or not these liver preservation methods can be combined [7].

Machine perfusion is associated with declines in primary non-function, graft failure, and biliary complications. For liver ex-vivo preservation the standard of organ preservation has not established, contrary to the kidney ex-vivo preservation where the hypothermic perfusion has become the standard [8-10].

The process of cold and warm ischemia followed by a reperfusion period is specific to liver transplantation, and is the primary cause of cellular damage [11]. Ischemia-reperfusion (I/R) injury compromises mitochondrial function and bioenergetics, particularly during reperfusion when the readmission of oxygen increases the production of reactive oxygen species $[12,13]$. We aimed to investigate mitochondrial function and cellular bioenergetics at different temperatures in an experimental model of ex-vivo liver transplantation, with a particular focus on the reperfusion phase.

\section{Materials and Methods}

The materials and methods used in this study have been described in detail previously [13].

\section{Animals}

Twelve-week-old male Wistar rats (Rattus norvegicus) weighing 320-350 g were purchased from Charles River (Charles River, Lyon, France). Upon arrival, the animals acclimatized for 1 week, and they were housed in an environment comprising controlled temperature and humidity and 12-h light-dark cycles, and given unlimited access to standard rodent food and acidified water. The study's protocol was approved by the Animal Ethics Committee at the University of Coimbra's Faculty of Medicine (ORBEA 150 2016/04112016, April 11, 2016).
All of the studies were conducted in accordance with the principles and procedures in the EU (1986/609/EEC and 2010/63/EU), Federation of European Laboratory Animal Science Associations, and Animal Research: Reporting of In Vivo Experiments (ARRIVE) guidelines, and they were approved by the Animal Care Committee at the Center for Neurosciences and Cell Biology, University of Coimbra. We also applied the principles of the ARRIVE guidelines to data management and interpretation, and we minimized the number of animals used and their suffering.

\section{Chemicals and reagents}

Except when noted, all of the chemicals and reagents were purchased from Sigma-Aldrich Corporation (St. Louis, MO, USA). All of the reagents and chemicals used were of the highest commercially available purity.

\section{Surgical protocol}

The surgical procedures were performed under anesthesia induced by ketamine $(50 \mathrm{mg} / \mathrm{kg})$ and chlorpromazine $(50 \mathrm{mg} / \mathrm{kg})$, provided by the same operator. A median laparotomy was performed, and the liver was mobilized by dividing the hepatic ligaments. The experimental model of ex-vivo liver transplantation comprised the introduction of a cannula into the portal vein and hepatic perfusion with an organ preservation solution (Celsior ${ }^{\circledR}$ ) at $4^{\circ} \mathrm{C}$ for $10 \mathrm{~min}$. Then, we performed a total hepatectomy while keeping the cannula inside the portal vein. Adequate inflows and outflows were confirmed. Cold static preservation at $4^{\circ} \mathrm{C}$ was performed over $12 \mathrm{~h}$. Reperfusion was performed using a Langendorff system at $32^{\circ} \mathrm{C}$ or $37^{\circ} \mathrm{C}$ for $1 \mathrm{~h}$ with a mixture comprising 50\% Plasma-Lyte 148 and 50\% Krebs solution at $\mathrm{pH} 7.2$ that was supplemented with oxygen by a pressurized membrane oxygenator ( $\mathrm{pO} 2$, 400-500 mm Hg) [14] (Fig. 1).
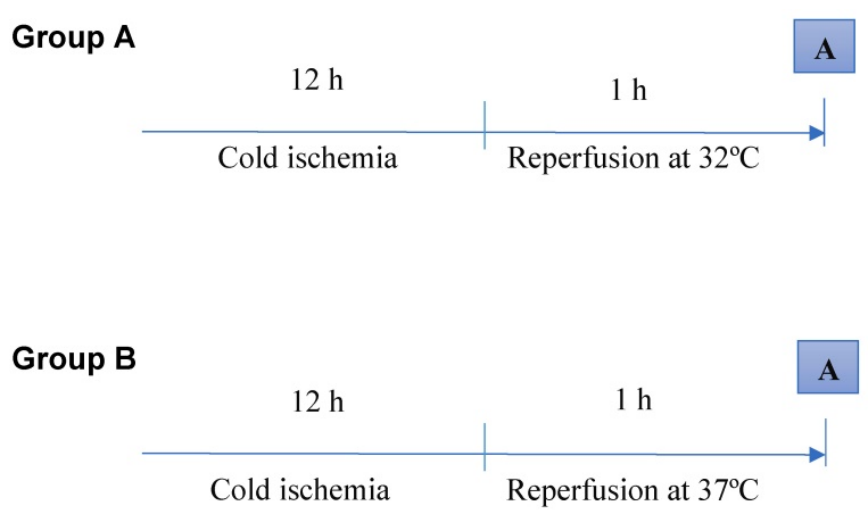

Figure 1. Schematic representation of reperfusion under hypothermic and normothermic conditions. Biopsies were taken at the end of the reperfusion time (A). The control group is not represented. Ten animals were analyzed per group. 
The animals $(n=30)$ were divided into three groups. The control group $(n=10)$ underwent a sham laparotomy, isolation of the hepatic pedicle, cannulation of the portal vein, perfusion with the organ preservation solution at $4^{\circ} \mathrm{C}$ for $10 \mathrm{~min}$, and total hepatectomy. Group A $(n=10)$ underwent a sham laparotomy, isolation of the hepatic pedicle, cannulation of the portal vein, perfusion with the organ preservation solution at $4^{\circ} \mathrm{C}$ for $10 \mathrm{~min}$, total hepatectomy, cold static preservation at $4^{\circ} \mathrm{C}$ for $12 \mathrm{~h}$, and reperfusion at $32^{\circ} \mathrm{C}$ with the Plasma-Lyte/Krebs solution ( $\mathrm{pH}$ 7.2) supplemented with oxygen for $1 \mathrm{~h}$. Group B ( $\mathrm{n}=10)$ underwent a sham laparotomy, isolation of the hepatic pedicle, cannulation of the portal vein, perfusion with the organ preservation solution at $4^{\circ} \mathrm{C}$ for $10 \mathrm{~min}$, total hepatectomy, cold static preservation at $4^{\circ} \mathrm{C}$ for $12 \mathrm{~h}$, and reperfusion at $37^{\circ} \mathrm{C}$ with the Plasma-Lyte/Krebs solution ( $\left.\mathrm{pH} 7.2\right)$ supplemented with oxygen for $1 \mathrm{~h}$.

\section{Mitochondrial isolation}

The mitochondria were isolated in a homogenization medium comprising $250 \mathrm{mM}$ sucrose, $10 \mathrm{mM}$ 4-(2-hydroxyethyl)-1-piperazineethanesulfonic acid (HEPES) ( $\mathrm{pH}$ 7.4), $0.5 \mathrm{mM}$ ethylene glycol-bis( $\beta$-aminoethyl ether)-N,N,N',N'tetraacetic acid (EGTA), and $0.1 \%$ fat-free bovine serum albumin (BSA) [15, 16]. After homogenization of the minced blood-free hepatic tissue, the homogenates were centrifuged at $800 \mathrm{~g}$ for $10 \mathrm{~min}$ at $4^{\circ} \mathrm{C}$. The supernatants were spun at $10000 \mathrm{~g}$ for 10 $\min$ at $4^{\circ} \mathrm{C}$ to pellet the mitochondria that were then resuspended in a final washing medium from which EGTA and BSA were omitted, and it was adjusted to $\mathrm{pH}$ 7.4. The protein content was determined using the biuret method calibrated with BSA.

\section{Mitochondrial membrane potential measurements}

The mitochondrial membrane potential was estimated using an ion-selective electrode to measure the distribution of tetraphenylphosphonium $\left(\mathrm{TPP}^{+}\right)$. The voltage response of the $\mathrm{TPP}^{+}$electrode to log $\left(\mathrm{TPP}^{+}\right)$was linear with a slope of $59 \pm 1$, and it conformed to the Nernst equation. The mitochondria $(1 \mathrm{mg})$ were suspended in standard medium $(1 \mathrm{~mL})$, comprising $130 \mathrm{mM}$ sucrose, $50 \mathrm{mM}$ potassium chloride, $5 \mathrm{mM}$ magnesium chloride, $5 \mathrm{mM}$ monopotassium phosphate, $50 \mathrm{mM}$ EDTA, $5 \mathrm{mM}$ HEPES ( $\mathrm{pH}$ 7.4), and $2 \mu \mathrm{M}$ rotenone, supplemented with $3 \mu \mathrm{L} \mathrm{TPP}{ }^{+}$. A matrix volume of $1.1 \mu \mathrm{L} / \mathrm{mg}$ protein was assumed. The reactions were carried out at $25^{\circ} \mathrm{C}$ in a temperature-controlled chamber surrounded by a water jacket with magnetic stirring. The membrane potential $(\mathrm{mV})$, depolarization $(\mathrm{mV})$, lag phase (s), and repolarization $(\mathrm{mV})$ were measured, and the readings were recorded in triplicate.

\section{Oxygen consumption measurements}

The oxygen consumption of the isolated mitochondria was determined using a Clark-type polarographic oxygen electrode (Oxygraph; Hansatech Instruments Ltd., King's Lynn, Norfolk, United Kingdom) [17]. Mitochondria (1 mg) were suspended in the standard medium $(1.4 \mathrm{~mL})$ with constant stirring at $25^{\circ} \mathrm{C}$, as described previously. The mitochondria were energized with succinate $(5 \mathrm{mM})$ and state 3 respiration was induced by adding adenosine diphosphate (ADP) (200 nmol). Oxygen consumption was also measured in the presence of 1 $\mu \mathrm{M}$ carbonyl cyanide-p-trifluoromethoxyphenylhydrazone. State 3 respiration and the respiratory control ratio were calculated according to Chance and Williams [18].

\section{Adenosine triphosphate measurements}

Liver adenosine triphosphate (ATP) was extracted using an alkaline extraction procedure [19]. The tissue ATP levels were measured using a luciferase/luciferin assay kit and a PerkinElmer Victor $3^{\mathrm{TM}}$ plate-reader fluorometer (PerkinElmer, Waltham, MA, USA), according to the manufacturers' instructions.

\section{Histological analysis}

The tissue samples were grossly inspected and divided, fixed in $4 \%$ formaldehyde, embedded in paraffin wax, cut into $4-\mu \mathrm{m}$ sections, and stained with hematoxylin and eosin (Polysciences Inc., Warrington, PA, USA) using a Sakura Autostainer-Prisma 81D (Sakura Finetek Europe B.V., Alphen aan den Rijn, The Netherlands). An experienced pathologist who was blinded to the experimental groups, examined the tissue sections using a light microscope (Nikon Eclipse 50i; Nikon Corporation, Tokyo, Japan), and images were obtained using a Nikon-Digital Sight DS-Fi1 camera (Nikon Corporation).

\section{Statistical analysis}

The continuous variables are presented as the means and standard errors of the means, unless otherwise specified. The normality of the data distributions was confirmed using the Kolmogorov-Smirnov and Shapiro-Wilk tests when indicated. Between-group comparisons were performed using Student's t-test, and differences among three or more groups were analyzed using a one-way analysis of variance for post hoc multiple comparisons. The statistical analyses were performed using IBM $^{\circledR S P S S}{ }^{\circledR}$ software, version 22.0 (IBM 
Corporation, Armonk, NY, USA). A value of $P<0.05$ was considered statistically significant.

\section{Results}

Reperfusion under hypothermic conditions was performed to evaluate its effects on mitochondrial function and bioenergetics. In this study, the cold ischemia $(12 \mathrm{~h})$ and reperfusion $(1 \mathrm{~h})$ times were maintained. Reperfusion occurred at $32^{\circ} \mathrm{C}$ in group $\mathrm{A}$ and at $37^{\circ} \mathrm{C}$ in group $\mathrm{B}$.

\section{Mitochondrial membrane potential}

The mitochondrial membrane potential estimates the phosphorylative capacity of isolated liver mitochondria. In this study, succinate was used to obtain the membrane potential data. A statistically significant difference in the mitochondrial membrane potential was evident between the groups (Table 1). Compared with the group subjected to normothermic reperfusion, hypothermic reperfusion significantly improved the parameters associated with mitochondrial function $(P<0.001)$. The lag phase declined in the hypothermic reperfusion group compared with that in the normothermic reperfusion group, thereby validating the measurement of the membrane potential data (Figs. 2 and 3 ).

Table 1. The membrane potentials and lag phases in the control group, group A (hypothermic reperfusion), and group B (normothermic reperfusion).

\begin{tabular}{llll}
\hline & \multicolumn{2}{l}{ Succinate } & \\
\cline { 2 - 4 } & Control & Group A & Group B \\
\hline Initial membrane potential (-mV) & $207.4 \pm 5.0$ & $199.6 \pm 1.5$ & $176.4 \pm 2.3^{* *}$ \\
Depolarization (mV) & $24.0 \pm 1.0$ & $21.7 \pm 1.1$ & $16.9 \pm 0.8^{\text {** }}$ \\
Lag phase (s) & $54.6 \pm 2.8$ & $60.8 \pm 1.0$ & $104.4 \pm 4.1^{\text {** }}$ \\
Repolarization (mV) & $194.7 \pm 7.7$ & $189.8 \pm 5.1$ & $172.6 \pm 2.1^{\text {** }}$
\end{tabular}

The data presented are the means and standard errors of the means. Statistically significant differences were found between groups A (hypothermic reperfusion) and $\mathrm{B}$ (normothermic reperfusion). ${ }^{* *} P<0.01$.

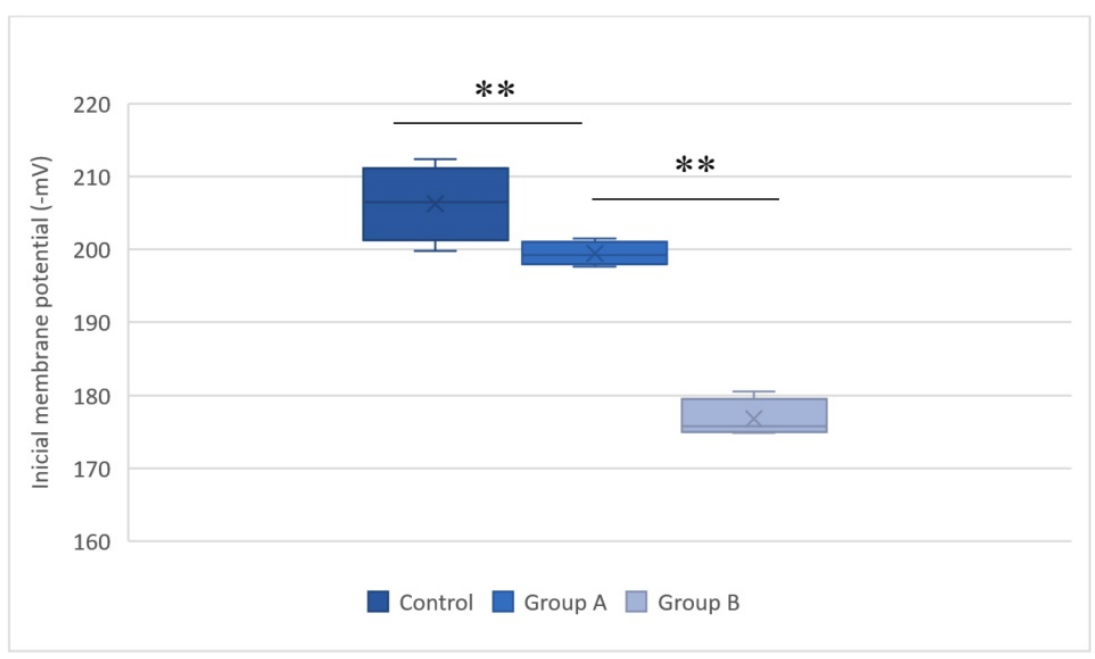

Figure 2. Initial membrane potentials $(\Delta \psi)$ in the control group, group $\mathrm{A}$ (hypothermic reperfusion), and group $\mathrm{B}$ (normothermic reperfusion). The membrane potentials were determined in the presence of succinate as a respiratory substrate. Phosphorylation was induced by adding adenosine diphosphate (100 nmol). A statistically significant difference was found between groups $A$ (hypothermic reperfusion) and B (normothermic reperfusion). ${ }^{* *} \mathrm{P}<0.01$.

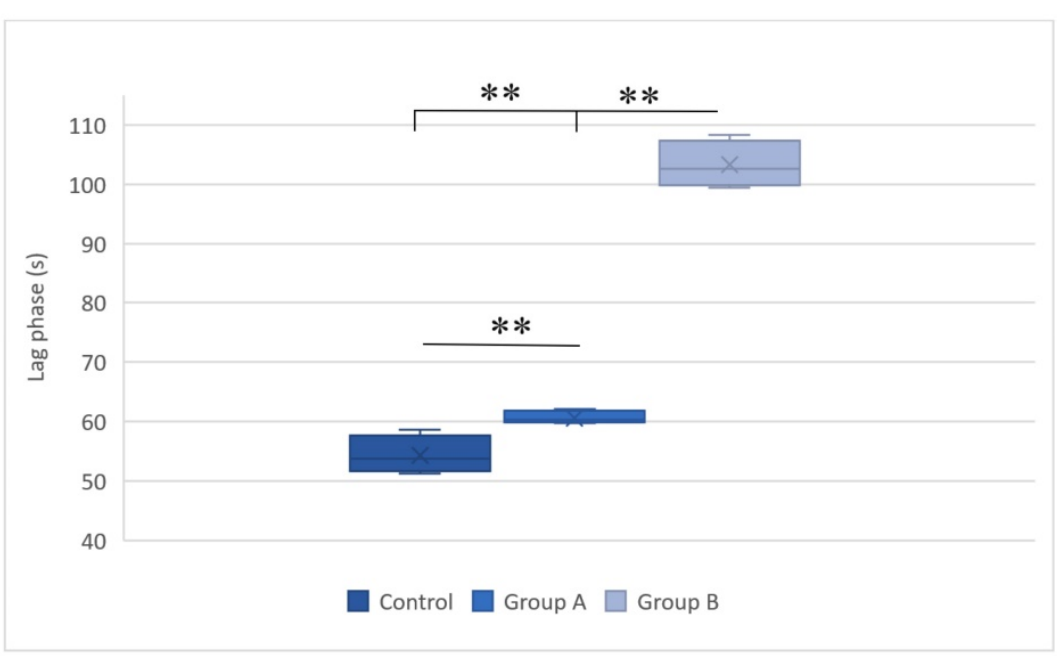

Figure 3. Lag phases in the control group, group $A$ (hypothermic reperfusion), and group $B$ (normothermic reperfusion) in the presence of succinate as a respiratory substrate. Phosphorylation was induced by adding adenosine diphosphate $(100 \mathrm{nmol})$. A statistically significant difference was found between groups $\mathrm{A}$ (hypothermic reperfusion) and B (normothermic reperfusion). $* * \mathrm{p}<0.01$. 


\section{Mitochondrial respiration}

The mitochondrial respiration measurements evaluated oxygen consumption after respiration was induced with succinate. Figures 4 and 5 summarize the results.

\section{Adenosine triphosphate content}

Figure 6 illustrates the ATP levels in the hepatic tissue subjected to hypothermic and normothermic reperfusion. Lower ATP levels were present in the tissues subjected to normothermic reperfusion compared with those in the tissues subjected to hypothermic reperfusion.

\section{Histological evaluation}

The histological evaluation of the hepatic tissue from the control group showed normal liver architecture. In Group A, the hepatic tissue was preserved, and there was no evidence of an inflammatory infiltrate, steatosis, or fibrosis. The structural integrity of the nuclei and organelles within the hepatocytes was maintained, and there was no evidence of necrosis or apoptosis. In Group B, the structure of the hepatic parenchyma was preserved, but the hepatocytes showed moderate-to-severe disassociation and some ballonization. The structural integrity of the organelles and nuclei within the hepatocytes was maintained, and neither apoptosis nor necrosis was visible (Figs. 7 and 8).

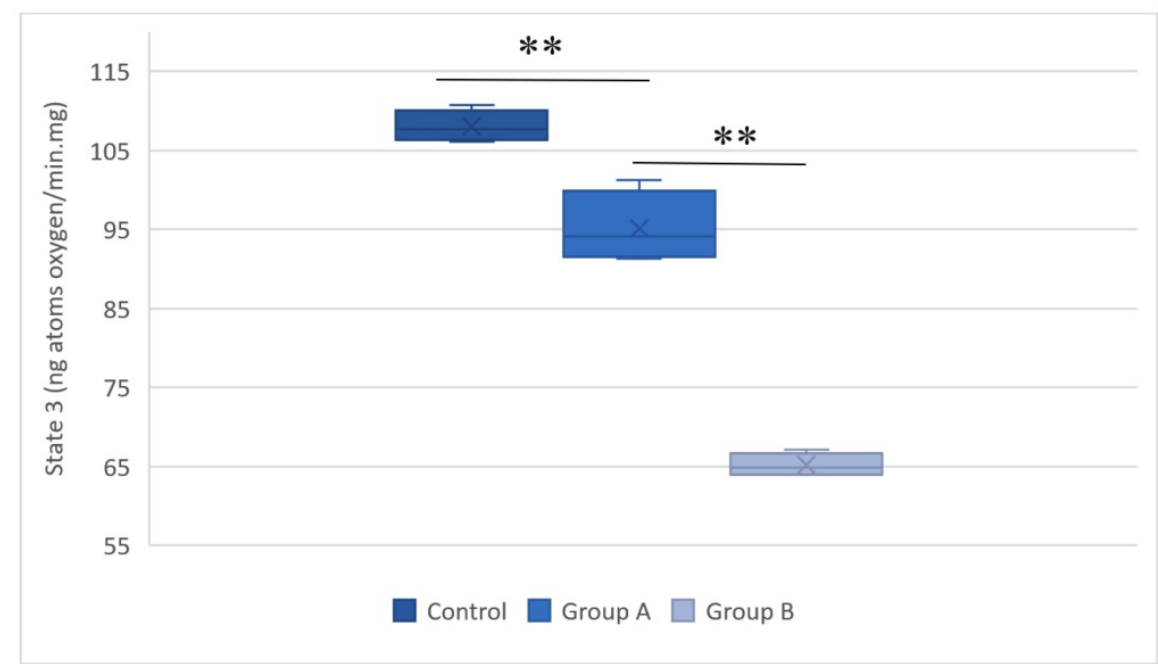

Figure 4. The respiratory state 3 values for the control group, group A (hypothermal reperfusion), and group B (normothermic reperfusion). The respiratory status was determined in the presence of succinate. A statistically significant difference was found between groups $A$ (hypothermic reperfusion) and $B$ (normothermic reperfusion). $* * P<$ 0.01 .

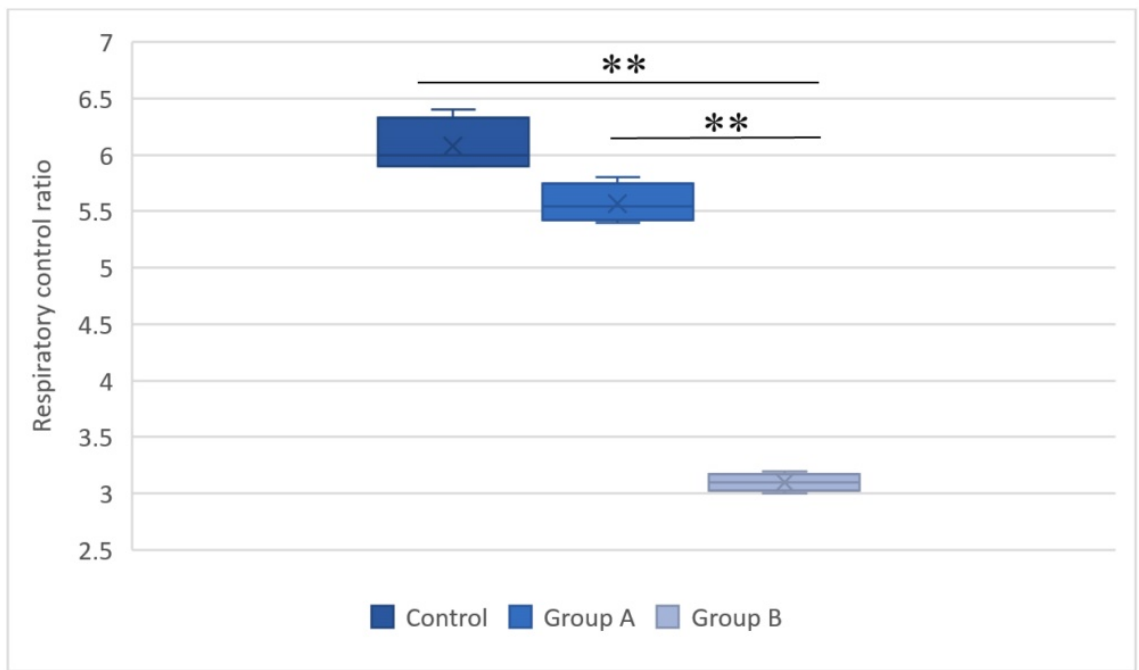

Figure 5. The respiratory control ratios in the control group, group $A$ (hypothermal reperfusion), and group $B$ (normothermic reperfusion). The respiratory control index was determined in the presence of succinate. A statistically significant difference was found between groups $A$ (hypothermic reperfusion) and $B$ (normothermic reperfusion). ${ }^{*} * \mathrm{P}<$ 0.01 . 


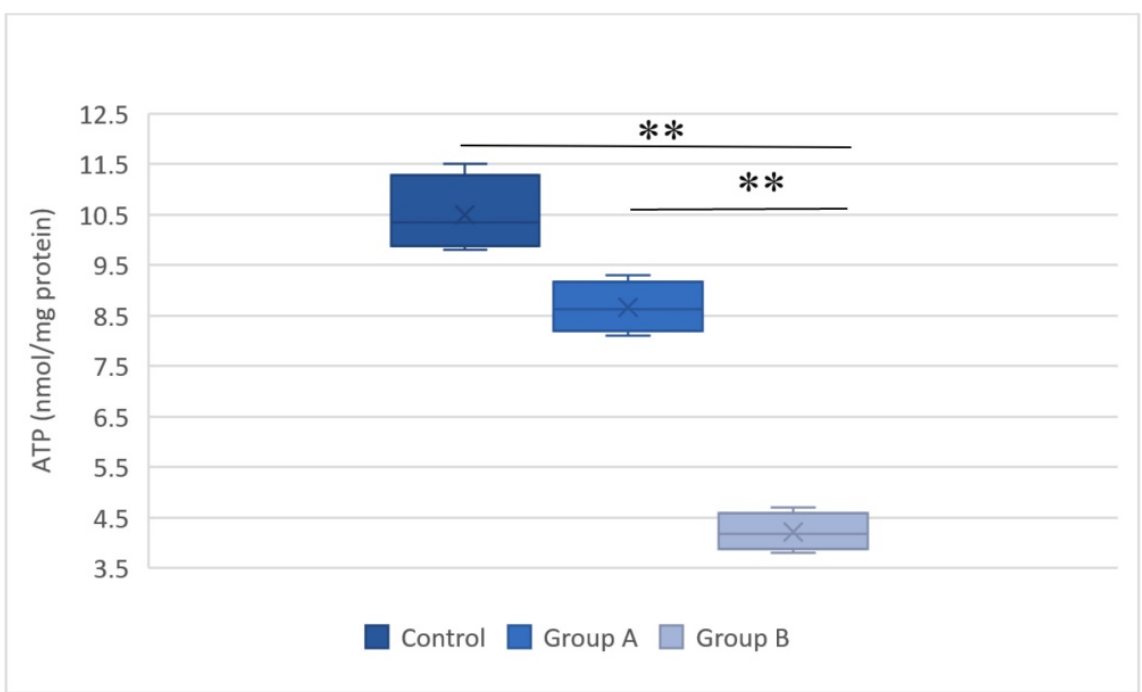

Figure 6. Representative plot of the adenosine triphosphate (ATP) levels in the hepatic tissue of the control group, group A (hypothermic reperfusion), and group B (normothermic reperfusion). A statistically significant difference was found between groups $A$ (hypothermic reperfusion) and $B$ (normothermic reperfusion). $* * P<0.01$. ATP, adenosine triphosphate.

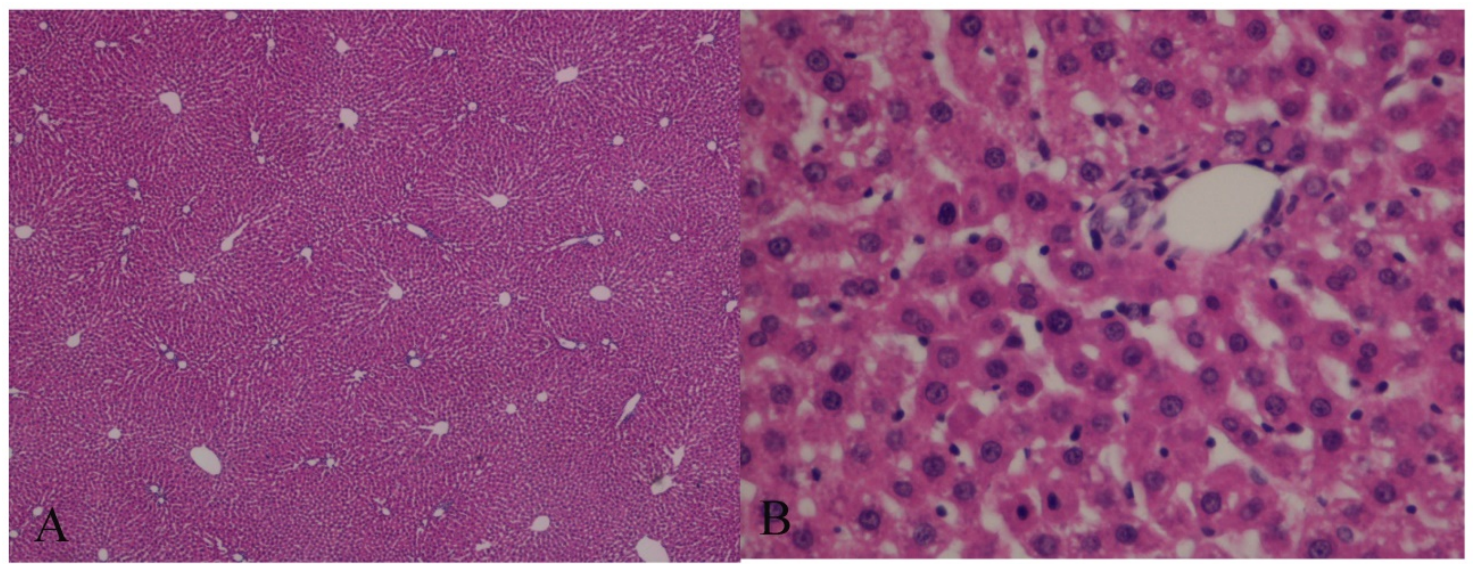

Figure 7. Hematoxylin and eosin (H\&E)-stained sections of hepatic tissue from the hypothermic reperfusion group. The hepatic sinusoids do not show endothelial injury, and the hepatocytes contained normal intracellular organelles and nuclei, with no signs of apoptotic or necrosis (A: H\&E 40x; B: H\&E 400x).

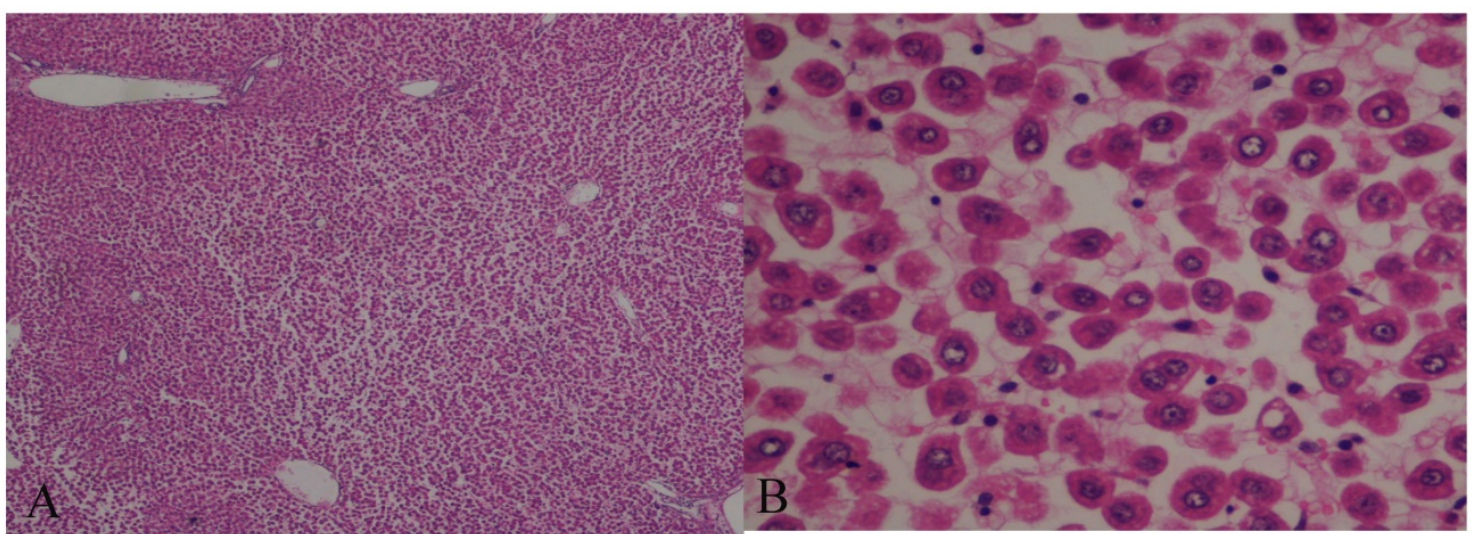

Figure 8. Hematoxylin and eosin (H\&E)-stained sections of hepatic tissue from the normothermic reperfusion group. The hepatic parenchyma architecture is preserved without lesions. There is moderate-to-severe disassociation of the hepatocytes. The hepatocytes contain normal nuclei and organelles, with no signs of necrosis or apoptosis (A: H\&E 40×; B: H\&E 400x).

\section{Discussion}

Animal models of hepatic transplantation are fundamental tools that have enhanced our understanding of the biological and immunological mechanisms involved in transplantation, and, thus, they have helped to answer some clinically relevant questions. 
The mouse is the most commonly used animal, and several mouse models have been developed [20]. In 1973, Lee et al. reported the first orthotopic liver transplantation in the rat, which consisted of performing an extracorporeal shunt between the portal and jugular vein at the recipient and posterior anastomosis of the implant to the hepatic vein, the portal vein and the recipient's aorta [21]. This very complex technique was abandoned, and 18 years later, following the development of vascular microsurgery techniques, Qian et al. developed a complex animal model of orthotopic liver transplantation. However, the investigations based on this model are very limited, because it requires a high level of microsurgical expertise and specific technical conditions. In addition, the high mortality rate caused by disruptions to hepatocellular function has limited the use of this animal model [22, 23].

Oscar Langendorff evaluated physiological and pathophysiological events within ex-vivo heart tissue, and, consequently, other animal models were developed that enabled ex-vivo evaluations of the liver, with an emphasis on I/ $R$ studies [24-26]. Previous ex-vivo liver transplantation studies are invaluable, because they have paved the way for the physiological and pathophysiological studies that are essential for the development of new ways to preserve the liver using dynamic preservation machines. These studies contribute to the development of dynamic preservation has altered the ways in which organs are perfused, preserved, and transported [5, 8, 27-30].

The animal models of ex-vivo liver transplantation are highly reproducible, and the results are not influenced by the complex surgical procedures of other models such as orthotopic liver transplant model. Despite these, the main limitation to these animal models of liver transplantation is related to the impossibility to evaluate pos-operative biomarkers of the liver function and the non-use of blood in the reperfusion phase [31].

Functional evaluations of mitochondrial activity in rodents have demonstrated that, like human beings, I/R clearly affects mitochondrial function, which has implications for bioenergetics, and translates into lower energy production efficiency [32, 33]. This ATP deficiency is sufficient to trigger changes in cellular metabolism; therefore, I/R injury in liver transplants interferes with the cellular bioenergetic balance.

Bigelow et al. introduced the concept of hypothermia to clinical practice in the early 1950 s, and they demonstrated its neuroprotective effect during cardiac surgery [34]. The benefits of hypothermia include the preservation of hepatic metabolism, and reductions in the inflammatory response and apoptosis during ischemia [35]. Recent experimental studies have shown that mild hypothermia at $32-34^{\circ} \mathrm{C}$ exerts a protective effect against warm I/R injury, but the mechanisms underlying this effect remain unclear [36]. Azoulay et al. studied patients who underwent complex liver surgery as a consequence of central hepatic tumors involving the inferior vena cava or the confluence of the hepatic veins with the vena cava, and they demonstrated the protective effect of hypothermic in-situ hepatic perfusion compared with total vascular exclusion for $>60 \mathrm{~min}$. This study's findings showed that patients who underwent hypothermic perfusion had a better I/R-induced injury tolerance, which translated into improved postoperative liver and kidney function and reduced morbidity [37].

In this study, we undertook a laboratory evaluation of the concept of hypothermia applied to reperfusion during hepatic transplantation; this involved a reperfusion temperature of $32^{\circ} \mathrm{C}$, which, according to experimental studies, provides more effective protection [38, 39]. Our study's findings showed statistically significant differences between the hypothermic reperfusion group and the normothermic reperfusion group regarding the mitochondrial membrane potential and respiration parameters, which were preserved to higher degrees in the hypothermic reperfusion group. In addition, the amount of ATP produced in the hepatic tissue from the hypothermic reperfusion group was higher than that recorded in the hepatic tissue from the normothermic reperfusion group.

Compared with normothermic reperfusion, hypothermic reperfusion reduced the effect of I/R on mitochondrial activity, thereby increasing the bioenergetic availability (42\%). Hence, applying hypothermic reperfusion to liver transplantation may be beneficial from a bioenergetic perspective, because mitochondrial function is preserved.

One of the main limitations regarding the use of hypothermia in clinical practice is the potential for coagulopathy. This seems to be associated with platelet dysfunction and damage to the enzymes in the coagulation cascade [40]. The risk of bleeding and the subsequent need for transfusions increase by approximately $20 \%$ for each degree Celsius decline in the core temperature. Hypothermia reduces the metabolic rate by $8 \%$ for each degree Celsius decline [41], which, for this study, would imply a $34 \%$ reduction in metabolic activity. In humans, the only clinical applications of hypothermia that have led to improved outcomes are extra-hospital cardiac arrest and neonatal asphyxia [42, 43]. To integrate the concept of hypothermic reperfusion into clinical practice and apply it to hepatic transplantation, 
further functional and technical studies will be necessary.

\section{Acknowledgments}

We are grateful for the support provided by the Sociedade Portuguesa de Transplantação (SPT), Astellas Pharma and Centro de Investigação do Meio Ambiente, Genética e Oncobiologia (CIMAGO), and Groupe IGL (Institut Georges Lopez).

\section{Funding Sources}

This work was supported by the Sociedade Portuguesa de Transplantação (SPT), Astellas Pharma, Centro de Investigação do Meio Ambiente, Genética e Oncobiologia (CIMAGO), Groupe IGL (Institut Georges Lopez). JST is the recipient of a postdoctoral scholarship from the Portuguese Fundação para a Ciência e a Tecnologia (SFRH/BPD/94036/2013).

\section{Authorship}

Rui Miguel Martins, José Guilherme Tralhão, Anabela Pinto Rolo and Carlos Marques Palmeira designed the research. Rui Miguel Martins, João Soeiro Teodoro, Anabela Pinto Rolo and Carlos Marques Palmeira performed the research. Rui Miguel Martins, João Soeiro Teodoro, Anabela Pinto Rolo and Carlos Marques Palmeira collected and analyzed the data. Emanuel Furtado and José Guilherme Tralhão contributed to data interpretation. Rui Caetano Oliveira performed the histologic analysis. Rui Miguel Martins wrote the manuscript.

\section{Competing Interests}

The authors have declared that no competing interest exists.

\section{References}

1. Bertuzzo VR, Cescon M, Odaldi F, Di Laudo M, Cucchetti A, Ravaioli M, et al. Actual Risk of Using Very Aged Donors for Unselected Liver Transplant Candidates: A European Single-center Experience in the MELD Era. Annals of surgery. 2017; 265: 388-96.

2. Flores A, Asrani SK. The donor risk index: A decade of experience. Liver transplantation : official publication of the American Association for the Study of Liver Diseases and the International Liver Transplantation Society. 2017; 23: 1216-25.

3. Minambres E, Suberviola B, Dominguez-Gil B, Rodrigo E, Ruiz-San Millan JC, Rodriguez-San Juan JC, et al. Improving the Outcomes of Organs Obtained From Controlled Donation After Circulatory Death Donors Using Abdominal Normothermic Regional Perfusion. American journal of transplantation : official journal of the American Society of Transplantation and the American Society of Transplant Surgeons. 2017; 17: 2165-72.

4. Ruiz P, Gastaca M, Bustamante FJ, Ventoso A, Palomares I, Prieto M, et al. Favorable Outcomes After Liver Transplantation With Normothermic Regional Perfusion From Donors After Circulatory Death: A Single-Center Experience. Transplantation. 2018.

5. Barbas AS, Goldaracena N, Dib MJ, Selzner M. Ex-vivo liver perfusion for organ preservation: Recent advances in the field. Transplantation reviews. 2016; 30: 154-60.

6. Goldaracena N, Barbas AS, Selzner M. Normothermic and subnormothermic ex-vivo liver perfusion in liver transplantation. Current opinion in organ transplantation. 2016; 21: 315-21.
7. Hosgood SA, Mohamed IH, Bagul A, Nicholson ML. Hypothermic machine perfusion after static cold storage does not improve the preservation condition in an experimental porcine kidney model. The British journal of surgery. 2011; 98: 943-50.

8. Marecki H, Bozorgzadeh A, Porte RJ, Leuvenink HG, Uygun K, Martins PN. Liver ex situ machine perfusion preservation: A review of the methodology and results of large animal studies and clinical trials. Liver transplantation : official publication of the American Association for the Study of Liver Diseases and the International Liver Transplantation Society. 2017; 23: 679-95.

9. Jayant K, Reccia I, Virdis F, Shapiro AMJ. The Role of Normothermic Perfusion in Liver Transplantation (TRaNsIT Study): A Systematic Review of Preliminary Studies. HPB surgery : a world journal of hepatic, pancreatic and biliary surgery. 2018; 2018: 6360423.

10. Schlegel A, Dutkowski P. Impact of Machine Perfusion on Biliary Complications after Liver Transplantation. International journal of molecular sciences. 2018; 19.

11. Robertson FP, Fuller BJ, Davidson BR. An Evaluation of Ischaemic Preconditioning as a Method of Reducing Ischaemia Reperfusion Injury in Liver Surgery and Transplantation. Journal of clinical medicine. 2017; 6.

12. Ma Z, Xin Z, Di W, Yan X, Li X, Reiter RJ, et al. Melatonin and mitochondrial function during ischemia/reperfusion injury. Cellular and molecular life sciences : CMLS. 2017; 74: 3989-98.

13. Martins RM, Pinto Rolo A, Soeiro Teodoro J, Furtado E, Caetano Oliveira R, Tralhao JG, et al. Addition of Berberine to Preservation Solution in an Animal Model of Ex Vivo Liver Transplant Preserves Mitochondrial Function and Bioenergetics from the Damage Induced by Ischemia/Reperfusion. International journal of molecular sciences. 2018; 19.

14. Gores GJ, Kost LJ, LaRusso NF. The isolated perfused rat liver: conceptual and practical considerations. Hepatology. 1986; 6: 511-7.

15. Varela AT, Simoes AM, Teodoro JS, Duarte FV, Gomes AP, Palmeira $\mathrm{CM}$, et al. Indirubin-3'-oxime prevents hepatic I/ $\mathrm{R}$ damage by inhibiting GSK-3beta and mitochondrial permeability transition. Mitochondrion. 2010; 10: 456-63.

16. Palmeira CM, Moreno AJ, Madeira VM. Interactions of herbicides 2,4-D and dinoseb with liver mitochondrial bioenergetics. Toxicology and applied pharmacology. 1994; 127: 50-7.

17. Rolo AP, Oliveira PJ, Moreno AJ, Palmeira CM. Bile acids affect liver mitochondrial bioenergetics: possible relevance for cholestasis therapy. Toxicological sciences : an official journal of the Society of Toxicology. 2000; 57: 177-85.

18. Chance B, Williams GR. Respiratory enzymes in oxidative phosphorylation. VI. The effects of adenosine diphosphate on azide-treated mitochondria. The Journal of biological chemistry. 1956; 221: 477-89.

19. Stocchi V, Cucchiarini L, Magnani M, Chiarantini L, Palma P, Crescentini G. Simultaneous extraction and reverse-phase high-performance liquid chromatographic determination of adenine and pyridine nucleotides in human red blood cells. Analytical biochemistry. 1985; 146: 118-24.

20. Czigany Z, Iwasaki J, Yagi S, Nagai K, Szijarto A, Uemoto S, et al. Improving Research Practice in Rat Orthotopic and Partial Orthotopic Liver Transplantation: A Review, Recommendation, and Publication Guide. European surgical research Europaische chirurgische Forschung Recherches chirurgicales europeennes. 2015; 55: 119-38.

21. Lee S, Charters AC, Chandler JG, Orloff MJ. A technique for orthotopic liver transplantation in the rat. Transplantation. 1973; 16: 664-9.

22. Chen J, Gong W, Ge F, Huang T, Wu D, Liang T. A review of various techniques of mouse liver transplantation. Transplantation proceedings. 2013; 45: 2517-21.

23. Qian SG, Fung JJ, Demetris AV, Ildstad ST, Starzl TE. Orthotopic liver transplantation in the mouse. Transplantation. 1991; 52: 562-4.

24. Varela AT, Rolo AP, Palmeira CM. Fatty liver and ischemia/reperfusion: are there drugs able to mitigate injury? Current medicinal chemistry. 2011; 18: 4987-5002.

25. Bell RM, Mocanu MM, Yellon DM. Retrograde heart perfusion: the Langendorff technique of isolated heart perfusion. Journal of molecular and cellular cardiology. 2011; 50: 940-50.

26. Ferreira FM, Palmeira CM, Seica R, Santos MS. Alterations of liver mitochondrial bioenergetics in diabetic Goto-Kakizaki rats. Metabolism: clinical and experimental. 1999; 48: 1115-9.

27. Karimian N, Matton AP, Westerkamp AC, Burlage LC, Op den Dries S, Leuvenink HG, et al. Ex Situ Normothermic Machine Perfusion of Donor Livers. Journal of visualized experiments : JoVE. 2015: e52688.

28. Burlage LC, Karimian N, Westerkamp AC, Visser N, Matton APM, van Rijn R, et al. Oxygenated hypothermic machine perfusion after static cold storage improves endothelial function of extended criteria donor livers. 
HPB : the official journal of the International Hepato Pancreato Biliary Association. 2017; 19: 538-46.

29. Dutkowski P, Linecker M, DeOliveira ML, Mullhaupt B, Clavien PA. Challenges to liver transplantation and strategies to improve outcomes. Gastroenterology. 2015; 148: 307-23.

30. Schlegel A, Kron P, Graf R, Dutkowski P, Clavien PA. Warm vs. cold perfusion techniques to rescue rodent liver grafts. Journal of hepatology. 2014; 61: 1267-75.

31. Beal EW, Dumond C, Kim JL, Akateh C, Eren E, Maynard K, et al. A Small Animal Model of Ex Vivo Normothermic Liver Perfusion. Journal of visualized experiments : JoVE. 2018.

32. Budai A, Horvath G, Tretter L, Radak Z, Koltai E, Bori Z, et al. Mitochondrial function after associating liver partition and portal vein ligation for staged hepatectomy in an experimental model. The British journal of surgery. 2019; 106: 120-31.

33. Go KL, Lee S, Zendejas I, Behrns KE, Kim JS. Mitochondrial Dysfunction and Autophagy in Hepatic Ischemia/Reperfusion Injury. BioMed research international. 2015; 2015: 183469.

34. Bigelow WG, Callaghan JC, Hopps JA. General hypothermia for experimental intracardiac surgery; the use of electrophrenic respirations, an artificial pacemaker for cardiac standstill and radio-frequency rewarming in general hypothermia. Annals of surgery. 1950; 132: 531-9.

35. Miao YF, Wu H, Yang SF, Dai J, Qiu YM, Tao ZY, et al. 5'-adenosine monophosphate-induced hypothermia attenuates brain ischemia/reperfusion injury in a rat model by inhibiting the inflammatory response. Mediators of inflammation. 2015; 2015: 520745.

36. Xiao Q, Ye Q, Wang W, Xiao J, Fu B, Xia Z, et al. Mild hypothermia pretreatment protects against liver ischemia reperfusion injury via the PI3K/AKT/FOXO3a pathway. Molecular medicine reports. 2017; 16: 7520-6.

37. Azoulay D, Eshkenazy R, Andreani P, Castaing D, Adam R, Ichai P, et al. In situ hypothermic perfusion of the liver versus standard total vascular exclusion for complex liver resection. Annals of surgery. 2005; 241: 277-85.

38. Behrends M, Hirose R, Serkova NJ, Coatney JL, Bedolli M, Yardi J, et al. Mild hypothermia reduces the inflammatory response and hepatic ischemia/reperfusion injury in rats. Liver international : official journal of the International Association for the Study of the Liver. 2006; 26: 734-41.

39. Niemann CU, Choi S, Behrends M, Hirose R, Noh J, Coatney JL, et al. Mild hypothermia protects obese rats from fulminant hepatic necrosis induced by ischemia-reperfusion. Surgery. 2006; 140: 404-12.

40. Michelson AD, MacGregor H, Barnard MR, Kestin AS, Rohrer MJ, Valeri CR. Reversible inhibition of human platelet activation by hypothermia in vivo and in vitro. Thrombosis and haemostasis. 1994; 71: 633-40.

41. Suga $\mathrm{H}$, Goto $\mathrm{Y}$, Igarashi $\mathrm{Y}$, Yasumura $\mathrm{Y}$, Nozawa $\mathrm{T}$, Futaki $\mathrm{S}$, et al. Cardiac cooling increases Emax without affecting relation between $\mathrm{O} 2$ consumption and systolic pressure-volume area in dog left ventricle. Circulation research. 1988; 63: 61-71.

42. Arrich J, European Resuscitation Council Hypothermia After Cardiac Arrest Registry Study G. Clinical application of mild therapeutic hypothermia after cardiac arrest. Critical care medicine. 2007; 35: 1041-7.

43. Kracer B, Hintz SR, Van Meurs KP, Lee HC. Hypothermia therapy for neonatal hypoxic ischemic encephalopathy in the state of California. The Journal of pediatrics. 2014; 165: 267-73. 